\title{
Decisions to treat or not to treat pneumonia in demented psychogeriatric nursing home patients: development of a guideline
}

Jenny T van der Steen, Martien T Muller, Marcel E Ooms, Gerrit van der Wal and Miel W Ribbe Vrije Universiteit, Amsterdam and Nursing Home Naarderheem, Bussum, the Netherlands

\begin{abstract}
Non-treatment decisions concerning demented patients are complex: in addition to issues concerning the health of patients, ethical and legal issues are involved. This paper describes a method for the development of a guideline that clarifies the steps to be taken in the decision making process whether to forgo curative treatment of pneumonia in psychogeriatric nursing home patients.

The method of development consisted of seven steps. Step 1 was a literature study from which ethical, juridical and medical factors concerning the patient's health and prognosis were identified. In step 2, a questionnaire was sent to 26 nursing home physicians to determine the relative importance of these factors in clinical practice. In a meeting of nine experienced physicians (step 3), the factors identified in step 2 were confirmed by most of these professionals. To prevent the final guideline being too directive, a concept guideline that included ethical and legal aspects was designed in the form of a "checklist of considerations" (step 4). Experts in the fields of nursing home medicine, ethics and law reviewed and commented on the concept guideline (step 5). The accordingly adapted "checklist of considerations" was tested in a pilot study (step 6), after which all experts endorsed the checklist (step 7).

The resulting "checklist of considerations" structures the decision making process according to three primary domains: medical aspects, patient's autonomy, and patient's best interest (see annex at end of paper).

(Fournal of Medical Ethics 2000;26:114-120)
\end{abstract}

Keywords: Decision making; medical futility; patien advocacy; pneumonia; practice guidelines; nursing homes

\section{Introduction}

Physicians involved in the care of elderly patients with a limited life expectancy are often confronted with the dilemma of whether treatment should be given or should be considered ineffective or unde- sirable. Decision making is particularly complicated with regard to incompetent patients, for example in the case of resuscitation and hospitalisation. This problem is paramount when considering the administration of antibiotics to demented nursing home patients with pneumonia. ${ }^{1}$ Curative treatment, which is aimed at achieving cure of the pneumonia, does not necessarily result in an improvement in physical or mental health status. However, refraining from curative treatment and providing only palliative treatment, solely aimed at alleviating symptoms to improve the patient's wellbeing, could imply that death is hastened. However, in addition to the medical considerations mentioned above, ethical and legal issues are involved as well, which further complicates the decision making process.

In general, guidelines can be a support by systematically addressing the various aspects involved in the decision making process. Medical guidelines, especially when evidence-based, can be quite directive. However, when juridical and especially ethical factors are to be considered as well, the "good" decision is not always as clear cut. The physician has to balance the relative importance of many, possibly conflicting, considerations to come to a decision. Therefore, the requirements for this type of guideline are quite different from the requirements for the traditional medical guidelines.

This paper describes a method of constructing guidelines for decision making concerning demented nursing home patients. This method was used to develop a guideline for do-not-treat decisions in nursing home patients with pneumonia. Pneumonia was chosen because of its high incidence in nursing home patients, and the associated high morbidity and mortality rates. ${ }^{2-5}$ An outline of the "checklist of considerations" is presented in the annex, and a slightly adapted front page in table 1 . 
Table 1 Slightly adapted version of the front page of the 'checklist of considerations'

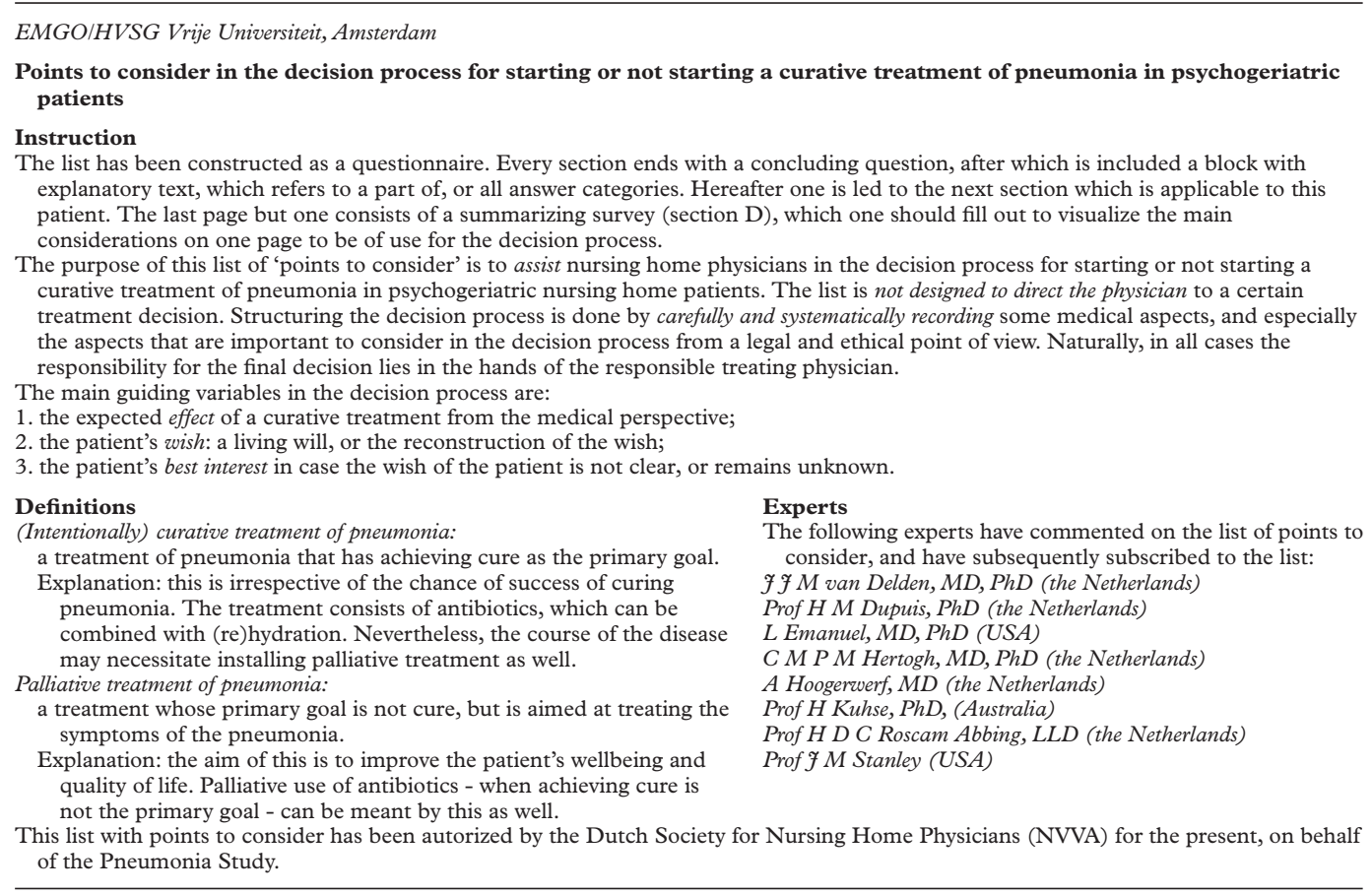

C EMGO-Institute August 1997

\section{Methods}

STEP 1: STUDY OF LITERATURE

The Medline database was used to search the medical literature from 1987 to 1994 , for papers dealing with prognostic factors and other possible factors that can play a role in the decision making process about whether to treat pneumonia or other infections curatively. Only those studies were selected in which at least some of the participants were psychogeriatric nursing home patients. The bibliographies of all the papers identified were reviewed, as well as the indices (1987-1993) of relevant journals that were not included in the Medline database. The literature search was repeated twice during the whole process in order to identify more recent literature.

STEP 2: INFORMATION FROM CLINICAL PRACTICE The aim of this step was: a) to examine the relative importance in clinical practice of the medical, juridical and ethical factors identified in the literature search, and b) to identify additional factors which could be considered important. For this purpose, a questionnaire was designed and sent to a jury of 26 nursing home physicians (NHPs) who had experience in nursing home medical practice and were associated with the university. The questionnaire was anonymous. Table 2 shows the topics that were addressed.

\section{STEP 3: CONSENSUS MEETING OF MEDICAL}

PROFESSIONALS

A meeting of nine experienced NHPs was held to investigate the need for this specific guideline and to reach consensus about the factors (medical, ethical, juridical and also procedural aspects) to be included in such a guideline, based on the results of the literature search and the questionnaire, as well as their expert opinion. In addition, how certain they were about the decision being the right one was discussed.

\section{STEP 4: DESIGN OF A CONCEPT GUIDELINE}

As information and consensus on the medical factors determining the usefulness of curative treatment for pneumonia were lacking, it was decided to develop a "checklist of considerations", based mainly on ethical and juridical issues. Medical issues were addressed in general terms only.

STEP 5: CONSULTATION OF (INTER)NATIONAL EXPERTS

To ensure widespread support for the "checklist of considerations", five national and three 
116 Decisions to treat or not to treat pneumonia in demented psychogeriatric nursing home patients: development of a guideline

Table 2 Topics addressed and form of questions on the questionnaire for nursing home physicians on important factors for the decision to treat or not to treat pneumonia curatively in psychogeriatric patients (step 2)

\begin{tabular}{|c|c|c|}
\hline Topic & Form of questions & Analysis \\
\hline $\begin{array}{l}\text { 1. The individual value that is attached to factors } \\
\text { concerning the patient's health status }\end{array}$ & $\begin{array}{l}\text { a list of factors with a 5-point scale to rate the } \\
\text { importance of the factor }\end{array}$ & descriptive \\
\hline $\begin{array}{l}\text { 2. Factors considered important but not included } \\
\text { under } 1\end{array}$ & $\begin{array}{l}\text { open-ended question with a 3-point scale to } \\
\text { rate the importance of the factor }\end{array}$ & descriptive \\
\hline $\begin{array}{l}\text { 3. The importance and role of family or other } \\
\text { representatives of the patient in the decision } \\
\text { making process }\end{array}$ & set of pre-structured questions & descriptive \\
\hline $\begin{array}{l}\text { 4. The importance and role of the nursing staff in the } \\
\text { decision making process }\end{array}$ & set of pre-structured questions & descriptive \\
\hline $\begin{array}{l}\text { 5. Decisive status (ie importance for the outcome of } \\
\text { the decision) of the already mentioned factors }\end{array}$ & $\begin{array}{l}\text { list of factors rated for importance on an } \\
\text { interval scale from } 0 \text { (unimportant) to } 10 \\
\text { (important) }\end{array}$ & $\begin{array}{l}\text { calculation of a mean value, } \\
\text { median value and mode of } \\
\text { each item }\end{array}$ \\
\hline
\end{tabular}

international experts in the fields of nursing home medicine, ethics and law were consulted. They were sent the conceptual, that is to say, the initial "checklist of considerations", and a questionnaire containing questions about their agreement or disagreement with each separate section of the list and the usefulness of the checklist as a whole. The experts were asked to state the reason for any disagreements and to suggest alternatives.

STEP 6: PILOT STUDY

Subsequently, a pilot study was performed to detect potential misinterpretation of the text and to evaluate the practical applicability of the checklist. Five nursing home physicians were asked to use the checklist either for two consecutive patients for whom they made a decision as to whether to treat pneumonia curatively, or else to complete it for two previous cases.

STEP 7: APPROVAL AND AUTHORISATION

In order to obtain a high level of professional acceptance, the "checklist of considerations" was submitted to the international experts of step 5 for approval. Partial approval or approval with specific individual comments, was also an option. Finally, in order to obtain the status of a national guideline, the Dutch Society for Nursing Home Physicians (NVVA) was asked to authorise the "checklist of considerations".

\section{Results}

The literature review identified reports and a discussion paper, ${ }^{6}$ as well as many opinionative articles potentially related to withholding curative treatment in psychogeriatric nursing home patients. Besides these, Dutch reports from leading societies on the acceptability of terminating life in incompetent patients were identified ${ }^{7-10}$ along with the national Dutch Law on the Medical Treatment Agreement (1995). Factors concerning health status and prognosis that could play a role in the decision making process were reported on in numerous studies of community-acquired pneumonia in adult hospitalised patients; these were reviewed in a meta-analysis in 1996 by Fine et al. ${ }^{11}$ Prognostic information concerning treatment of patients with fever ${ }^{12-14}$ or lower respiratory tract infections ${ }^{15}$ in demented (nursing home) patients was available, but not specifically for pneumonia patients. Specific guidelines for seriously demented patients appeared to be available neither in the Netherlands, nor elsewhere. However, the need to implement standards for decision making in the care of severely demented patients was confirmed by several authors. ${ }^{16-18}$ Repetition of the literature search did not deliver any specific guideline on whether to treat pneumonia curatively in elderly patients. Recently, a report was published on the treatment of elderly pneumonia patients concerning, however, mainly hospitalised patients. ${ }^{19}$ Two recent studies on pneumonia mortality in nursing home patients treated with antibiotics did reveal some prognostic factors ${ }^{20}{ }^{21}$ which are directly relevant to the "checklist of considerations".

The results of the questionnaire on clinical practice (step 2) are presented in table 3. Twenty NHPs $(77 \%)$ responded. Almost all respondents (95\%) rated the "overall" physical condition of the patient "important" or "very important" when making the treatment decision. The estimated life expectancy $(75 \%)$, active or passive communication skills $(60 \%)$, and the severity of dementia $(60 \%)$ were considered either very important or important factors by most of the responding NHPs as well. When asked about important somatic factors that were not mentioned in the questionnaire, the NHPs gave a wide variety of answers. Most frequently mentioned $(n=6)$ was the patient's wellbeing, also described as "mood" or "will to live", before the onset of pneumonia. Sixteen additional factors were mentioned, most of them related to the patient's prognosis or suffering. According to $55 \%$ of the NHPs, contact 
Table 3 The value attributed to medical factors concerning the patient's health status (table 2, topic 1) when making treatment decisions concerning psychogeriatric patients with pneumonia, as rated by 20 nursing home physicians (NHPs)

\begin{tabular}{|c|c|c|c|c|c|}
\hline \multirow[b]{2}{*}{ Medical factors } & \multicolumn{5}{|c|}{ Degree of importance (\% of NHPs) } \\
\hline & $\begin{array}{l}1 \text { (very } \\
\text { unimportant) }\end{array}$ & 2 (unimportant) & $\begin{array}{l}3 \text { (slightly } \\
\text { important) }\end{array}$ & 4 (important) & $\begin{array}{l}5 \text { (very } \\
\text { important) }\end{array}$ \\
\hline Overall physical health status & 0 & 0 & 5 & 65 & 30 \\
\hline Estimated life expectancy & 0 & 0 & 25 & 45 & 30 \\
\hline Communication skills (active and passive) ${ }^{\star}$ & 0 & 15 & 20 & 35 & 25 \\
\hline Severity of dementia & 0 & 10 & 30 & 40 & 20 \\
\hline Pressure ulcers & 0 & 20 & 35 & 35 & 10 \\
\hline Mobility & 20 & 45 & 25 & 10 & 0 \\
\hline $\mathrm{ADL}$ & 10 & 50 & 35 & 5 & 0 \\
\hline Incontinence & 50 & 40 & 10 & 0 & 0 \\
\hline
\end{tabular}

${ }^{\star} 1 \mathrm{NHP}$ did not answer this question.

with the family of the patients (topic 3 in table 2 ) should always take place the moment pneumonia occurs. Different reasons were given for this: reconstructing the wish of the patient, asking for the family's opinion on the best treatment, or merely informing them about the treatment decision. According to the remaining $45 \%$ of the NHPs, contact with the family was not always necessary, mainly when the patient's wish was already known, or when the family was not involved with the patient. All NHPs, however, were of the opinion that contact with the nursing staff should always take place. For this purpose, the same reasons as with "contact with the family" were mentioned. Less significance, however, was given to the role of the nursing staff in reconstructing the patient's wish (15\% for nursing staff, versus $35 \%$ for the family). As far as decisive factors are concerned, the highest scores for the degree of importance (median score 9 on a 10-point scale) were given to the items "the patient's health prior to the onset of pneumonia", "medical sense/futility to treat (non-)curatively", and "the previously expressed wish of the patient to be treated curatively". The "expected physical health status of the patient in case of cure (prognosis)" ranked fourth. Items with median and mode scores less than nine included the wish of the family and of the nursing staff to treat the patient curatively, the severity of dementia and success achieved by curative treatment of pneumonia in the past. Least important, according to most of the NHPs (mode 0), were comorbidity and the burden on the patient due to the treatment, or the burden on the patient due to the pneumonia itself.

The participating experienced professionals consulted during the consensus meeting (step 3) reported that the results of the questionnaire were on the whole in accordance with their concept of clinical practice. The professionals agreed that if no explicit wish had been expressed, the patient's physical condition before the onset of pneumonia was the most important criterion for determining whether or not to treat the patient curatively. There was no consensus, however, on which specific aspects of the patient's physical condition should be considered (for example, ongoing weight-loss, insufficient fluid intake, etc).

In general, the (reconstructed) wish of the patient was considered to be very important, though not always decisive. The wish of the family (ie not the reconstructed wish of the patient) and the opinion of the nursing staff could be considered in decision making, but should never be decisive. Nevertheless, the more a physician was in doubt, the more the opinion of family and nursing staff was taken into account. Predicting the outcome of a specific treatment for an individual patient was considered to be very difficult, although some professionals were reasonably confident that their estimates were usually accurate when prognostic factors such as the degree of dyspnoea, the presence of tachypnoea and the intake of fluids were taken into account. The necessity for a guideline concerning nontreatment decisions to do with pneumonia in demented nursing home patients was fully confirmed by six of the nine professionals. Of the remaining three, only one did not feel the need for any support by means of a guideline.

For the next step (step 4), the project group decided to construct the guideline in the form of a "checklist of considerations". A guideline in the form of a traditional protocol was considered to be too directive. The checklist was based on the results of the first three steps. A front-page (table 1) was added, explaining the origin, purpose, structure and definitions.

In the next step (step 5), all the invited experts agreed to take part in the expert panel and gave their comments on the first concept. The only major adaptation was made for the section "medical aspects". This section was cleared of ethical aspects, which were moved to a new "best interest" section. Possible harmful medical effects, 
118 Decisions to treat or not to treat pneumonia in demented psychogeriatric nursing home patients: development of a guideline

ie the "burden of treatment", were separated from other medical aspects. Some questions were reformulated to prevent biasing the physician.

As a result of the pilot study (step 6), further adaptations were made. The main adaptation concerned the summary, which until then determined the routing of the checklist. This proved to be impractical and confusing. The summary was made optional, for example one could give a short overview of a complex case.

In step 7, all the experts who were consulted in step 5 now approved of the "checklist of considerations" as a whole, though some of the experts still required minor (mainly textual) adaptations. Subsequently, the Dutch Society for Nursing Home Physicians (NVVA) granted authorisation for use of the checklist in an evaluation study.

\section{Discussion}

With the method described above, it proved to be possible to develop a nationally and internationally approved "checklist of considerations" for end-of-life decisions in psychogeriatric patients, ie the decision whether or not to treat pneumonia curatively. Though timeconsuming - it took three years to develop the complete checklist - the method guarantees input from the literature and the nursing home profession, as well as input from experts in other disciplines. Widespread support was obtained from renowned experts, as well as from the Dutch Society for Nursing Home Physicians, which will greatly enhance the acceptance of the guideline.

It has been widely accepted that physicians should be guided by four ethical principles: respect for autonomy, doing good, doing no harm, and justice. In daily practice, medical decision making is mainly guided by medical considerations. This is confirmed by the results of the questionnaire and the meeting of professionals, and is reflected in the "checklist of considerations", as medical effectiveness of the treatment is required and is considered first (doing good and doing no harm). However, information from the literature on prognostic factors was scarce and of poor quality, and, moreover, no consensus could be reached on these medical prognostic factors. Therefore, this aspect had to be presented in general terms, so that a physician could make his/her own judgment. The second main point of the "checklist of considerations"is the patient's wish. Most NHPs and professionals thought the wish of the patient expressed when the patient was still competent was important, though medical considerations prevailed, according to the questionnaire and the meeting of professionals. Of course, the patient's wish should be respected (au- tonomy). Most psychogeriatric patients, however, can no longer grasp the consequences of their decision, or are incapable of communicating their wishes. When direct information about the wish of the patient is not available, the family or representative should be asked to reconstruct the patient's wish. Though the wish of the family itself was not regarded as decisive, most of the NHPs and experts agreed that the family should be involved in the decision making process. The position of the nursing staff was also thought to be important. The fourth principle, justice, is implicitly reflected in the checklist: only costs and benefits for the individual, and not for the community, are at stake. In order to make a decision based on ethical principles, information about the patient characteristics that determine the course and consequences of pneumonia is also necessary. As these characteristics are still largely unknown, both the physician and the family are compelled to give their personal opinion of what is in the patient's best interest when the patient's wish is unknown. This constitutes the third main point on the "checklist of considerations".

Although the "checklist of considerations" has been developed for use by NHPs in the Netherlands, and for the specific decision about whether to treat pneumonia curatively in psychogeriatric patients, the problem addressed here is universal. Thus, the method may very well be applicable for developing guidelines to cover the broader scope of non-treatment decisions in incompetent patients. It took a long time to complete the development process, mainly due to the many refinements that had to be made. As these pitfalls can now be avoided, we are confident that developing a new guideline according to this method will be much less time-consuming. According to the nature and extent of the underlying evidence and international variations in law, the process of developing guidelines might need to be adapted for each end-of-life decision. If the literature does not provide sufficient basis for guideline formulation, other sources of information can be used (expert opinion, extrapolation of the results of studies with a different population, analysis of routinely collected data). ${ }^{22}$ The information provided by the ultimate users of the "checklist of considerations", ie NHPs, is especially important in terms of the applicability and acceptability of the guideline.

The relative weight of each prognostic factor will be evaluated in a subsequent prospective study, designed to produce data on prognosis (chance of cure, quality of life) of both curatively and palliatively treated patients. The resulting indicators for the prognosis will be included in the 
"checklist of considerations". Rigorous evaluation is needed to investigate the actual effect of guidelines on practice. ${ }^{23}$ Meanwhile, we have investigated the acceptance of the contents, and the applicability of the "checklist of considerations" in practice. A further paper, evaluating the "checklist of considerations" is currently submitted for publication.

Annex Summarising survey of the 'checklist of considerations'

Copy the results of the preceding pages, as far as applicable.

Completing the summary is optional.

A.1.6 Is an intentionally curative treatment indicated for this patient?

$\square$ yes, indicated $\square$ I don't know $\square$ no, not indicated

A physician is not compelled to act if this is not medically effective. Moreover, a request to treat can not be honoured if the treatment at issue is not in agreement with the medical professional standards. According to - among others - CAL, ${ }^{78}$ starting a treatment is undesirable if it is considered to be not medically effective, irrespective the wishes and opinions of the patient and other persons involved.

There should be a dialogue, however, with the nursing staff and the patient's representative(s), explaning the undesirability of installing treatment which is not effective.

A.2.3 How physically and/or psychically burdensome would the total curative treatment - antibiotics and (re)hydration - be for the patient?

$\square$ very burdensome $\quad \square$ somewhat burdensome $\square$ not or little burdensome

When choosing the best treatment, beside the medical effectivity, the burden of treatment plays a part.

B.1.4 Is the patient sufficiently mentally competent, and if so, what treatment does the patient want?

$\square$ insufficiently competent $\quad \square$ sufficiently competent, wants curative $\square$ sufficiently competent, wants palliative treatment treatment

In this situation, merely the present wish of the patient applies and the rules for informed consent must be adhered to. Neither a living will, nor family nor representative(s) play a role in the decision process.

B.2.9 What is the purport of the living will?

$\square$ unclear/absent $\square$ patient wants curative treatment $\square$ patient wants palliative treatment In the WGBO(Dutch law) a negative living will has been given a legal status. A physician is compelled to follow the will when the patient does not wish a curative treatment, unless there are sufficient grounds (as mentioned in B.2.5-B.2.8) not to do so. As a rule, there should be a dialogue with the nursing staff and the patient's representative(s). The living will, however, is decisive.

B.3.9 What is the purport of the reconstruction of the patient's will according to the representative(s)?

$\square$ absent/doubt/opposing opinions $\square$ intentionally curative treatment $\square$ palliative treatment

According to the WGBO, appointed as well as unappointed representatives have the authority to take decisions on the patient's behalf. The physician, however, retains his or her responsibility to test these decisions for medical effectiveness, and whether the representatives are actually reconstructing the wish of the patient (which has been tested in part B.3).

B.4.7 What is the purport of the reconstructed patient's wish according to the other involved professional carers?

$\square$ doubt/opposing opinions $\quad \square$ intentionally curative treatment $\quad \square$ palliative treatment
The nursing staff and other (para)medics are not authorized to make decisions. The treating physician retains this responsibility.

C.5 Which treatment seems to be in the patient's best interest?

$\square$ doubt/opposing opinions $\square$ intentionally curative treatment $\square$ palliative treatment

Finally, the physician bases his or her choice of the treatment on what is in the patient's best interest.

(c) EMGO-Institute 1997

\section{Acknowledgements}

We wish to thank A van Bemmel, MD; J F J M van Berkel, MD; V G M Chel, MD; W Deerenberg-Kessler, MD; J J M van Delden, MD, PhD; C M P M Hertogh, MD, PhD; J F Hoek, MD; P van Houten, MD; J van Willigen, $\mathrm{MD}$, all of whom are nursing home physicians, for participating in the consensus meeting. The valuable and often time-consuming contributions of the national and international experts as mentioned in table 1 are highly appreciated. We thank the Board of the Dutch Society for Nursing Home Physicians (NVVA) and G L Schut, $\mathrm{MD}, \mathrm{PhD}$, Chairman of the Quality Committee, for their work on the authorisation of the guideline and Ellen Kampers for her administrative work.

\section{Funding}

The study is funded by the Dutch Ministry of Public Health, Welfare and Sports (VWS). The pilot study was funded by Society "Het Zonnehuis".

Fenny $T$ van der Steen, $M S c$, is an Epidemiologist and Principal Researcher on the "Pneumonia Study" which has two main goals: identification of prognostic factors for pneumonia in psychogeriatric nursing home patients, and development and evaluation of the "checklist of considerations". In 1995/96 she performed a pilot study; in Fuly 1996 she was appointed as a PhD student in the Institute for Research in Extramural Medicine (EMGO-Institute) of the Vrije Universiteit, Amsterdam, the Netherlands, to continue with her main study on pneumonia. Data collection for 
120 Decisions to treat or not to treat pneumonia in demented psychogeriatric nursing home patients: development of a guideline

the main study was carried out in 61 nursing homes in the Netherlands. Martien T Muller, PhD, is a Social Gerontologist in the Department of General Practice, Nursing Home Medicine and Social Medicine of the Vrije Universiteit. He also works as a Social Gerontologist at the Nursing Home, Naarderheem, Bussum, the Netherlands. He is a member of the project group of the Pneumonia Study. Marcel E Ooms, MD, PhD, is Project Leader of the Pneumonia Study and is Epidemiologist and Senior Researcher in the Department of General Practice, Nursing Home Medicine and Social Medicine of the Vrije Universiteit. Gerrit van der Wal, MD, PhD, is Professor of Social Medicine in the Department of General Practice, Nursing Home Medicine and Social Medicine of the Vrije Universiteit. He is also a member of the project group of the Pneumonia Study. Miel W Ribbe, MD, PhD, is Professor of Nursing Home Medicine in the Department of General Practice, Nursing Home Medicine and Social Medicine of the Vrije Universiteit. He is also a member of the project group of the Pneumonia Study. All the authors, except for Martien Muller, are also employed by the Institute for Research in Extramural Medicine (EMGO-Institute) of the Vrije Universiteit. Requests for a copy of the guideline should be addressed to the first author. Correspondence address: Fenny $T$ van der Steen, $M S c$, EMGO-Institute, Vrije Universiteit, Amsterdam, Medical Faculty, Van der Boechorststraat 7, 1081 BT Amsterdam, the Netherlands. Tel. +31-20-4448205; fax +31-20-4448181/4448387; e-mail $\mathfrak{F T}$. van_Kampen.EMGO@Med.VU.nl

\section{References}

1 Hertogh CMPM, Ribbe MW. Ethical aspects of decisionmaking in demented patients: a report from the Netherlands. Alzheimer Disease and Associated Disorders 1996;10:11-19.

2 Cools HJM. Bacterial infections in the nursing home. [In Dutch] [dissertation]. The Hague: AVO, 1984.

3 Mott PD, Barker WH. Treatment decisions for infections occuring in nursing home residents. Fournal of the American Geriatrics Society 1988;36:820-4.

4 Marrie TJ, Durant H, Kwan C. Nursing home-acquired pneumonia - a case-control study. fournal of the American Geriatrics Society 1986;34:697-702.

5 Jackson MM, Fierer J, Barrett-Connor E, Fraser D, Klauber $\mathrm{MR}$, Hatch R, et al. Intensive surveillance for infections in a three-year study of nursing home patients. American fournal of three-year study of nursing hor
6 Stanley JM. The Appleton International Conference. Developing guidelines for decisions to forgo life-prolonging medical treatment. Fournal of Medical Ethics 1992;18:supplement.

7 Royal Dutch Medical Association. Commission on the acceptability of the termination of life (KNMG, CAL). Discussion paper on termination of life in the case of non-competent patients part III. Severely demented patients. [ In Dutch] Utrecht: KNMG, 1993.

8 Royal Dutch Medical Association. Commission on the acceptability of the termination of life (KNMG, CAL). Medical end of life: acting for incompetent patients. [In Dutch] Houten: Bohn hife: acting for incompetent pati

9 Dutch Society for Nursing Home Physicians (NVVA). Proceeding tactfully in psychogeriatric care. Assistance for the decision process by nursing nome physicians concerning patients becoming demented. [In Dutch] Utrecht: NVVA, 1996.

10 Dutch Society for Nursing Home Physicians (NVVA). Proceeding tactfully in psychogeriatric care. Assistance for the decision process by nursing home physicians concerning patients becoming demented [in Dutch]. Utrecht: NVVA, 1997.

11 Fine MJ, Smith MA, Carson CA, Mutha SS, Sankey SS, Weissfeld LA, et al. Prognosis and outcomes of patients with community-acquired pneumonia - a meta-analysis. Fournal of the American Medical Association 1996;275:134-41.

12 Brown NK, Thompson, DJ. Nontreatment of fever in extended-care facilities. New England fournal of Medicine 1979;

13 Fabiszewski KJ, Volicer B, Volicer L. Effect of antibiotic treatment on outcome of fevers in institutionalized Alzheimer patients. Fournal of the American Medical Association 1990;263: 3168-72

14 Hurley AC, Volicer B, Mahoney MA, Volicer L. Palliative fever management in Alzheimer patients: quality plus fiscal responsibility. Advances in Nursing Science 1993;16:21-32.

15 Mehr DR, Foxman B, Colombo P. Risk factors for mortality from lower respiratory infections in nursing home patients. The fournal of Family Practice 1992;34:585-91.

16 Braithwaite S, Thomasma DC. New guidelines on foregoing life-sustaining treatment in incompetent patients: an anticruelty policy. Annals of Internal Medicine 1986;104:711-15.

17 Doyal L, Wilsher D. Withholding and withdrawing life sustaining treatment from elderly people: towards formal guidelines. British Medical fournal 1994;308:1689-92.

18 Rango N. The nursing home resident with dementia - clinical care, ethics, and policy implications. Annals of Internal Medicine 1985;102:835-41.

19 Meehan TP, Fine MJ, Krumholz HM, Scinto JD, Galusha DH, Mockalis JT, et al. Quality of care, process, and outcomes in elderly patients with pneumonia. Fournal of the Medical Association 1997;278:2080-84.

20 Degelau J, Guay D, Pharm D, Straub K, Luxenberg, MG. Effectiveness of oral antibiotic treatment in nursing homeacquired pneumonia. fournal of the American Geriatrics Society 1995; $43: 245-51$.

21 Muder RR, Brennen C, Swenson DL, Wagener M. Pneumonia in a long-term care facility - a prospective study of outcome. Archives of Internal Medicine 1996;156:2365-70.

22 Gyorkos TW, Tannenbaum TN, Abrahamowicz M, Oxman $\mathrm{AD}$, Scott EAF, Millson ME, et al. An approach to the development of practice guidelines for community health interventions. Canadian Fournal of Public Heatlh 1994;85, suppl1: S8-S13.

23 Grimshaw JM, Russell IT. Effect of clinical guidelines on medical practice: a systematic review of rigorous evaluations. The Lancet 1993;342:1317-22. 